\title{
Importance of the swimbladder in acoustic scattering by fish: A comparison of gadoid and mackerel target strengths
}

\author{
Kenneth G. Foote \\ Department of Applied Mathematics, University of Bergen, 5014 Bergen, Norway \\ (Received 3 December 1979; accepted for publication 7 March 1980) \\ Previous determinations of the swimbladder contribution to the fish backscattering cross section have \\ been hindered by ignorance of the acoustic boundary conditions at the swimbladder wall. The present \\ study circumvents this problem by direct comparison of target strengths of three gadoid species and \\ mackerel - anatomically comparable fusiform fish which respectively possess and lack a swimbladder. \\ The relative swimbladder contribution to both maximum and averaged dorsal aspect backscattering cross \\ sections is shown to be approximately $90 \%$ to $95 \%$, which is higher than most other estimates. The new \\ results were established for fish of $29-$ to $42-\mathrm{cm}$ length and acoustic frequencies of 38 and $120 \mathrm{kHz}$.
}

PACS numbers: 43.80.Jz, 43.30.Dr, 43.30.Gv

\section{INTRODUCTION}

The importance of the swimbladder in acoustic scattering by physoclistous and physostomatous fish has long been recognized. ${ }^{1-17}$ There is conflicting evidence, however, for the magnitude of its contribution to the fish backscattering cross section. This may be due in part to systematic species and frequency differences in scattering properties, but undoubtedly also reflects the variety of methods which have been applied in its determination.

Experimental studies have been essentially comparative. Backscattering cross sections or target strengths of fish with intact swimbladders have been compared with measurements of the same fish with deflated, $2,5,14$ flooded, ${ }^{5}$ or model-substituted ${ }^{2,4}$ swimbladders. Comparisons have also been made with measurements on air-filled sacs with an equivalent volume $\mathrm{e}^{1,13}$ and solid swimbladder models. ${ }^{2}$ Theoretical studies have modelled the swimbladder as a gas-filled cylinder, ${ }^{7,8}$ spherical air bubble in water ${ }^{7}$ or in an elastic medium, ${ }^{6}$ spheroidal gas bubble, ${ }^{12}$ and spherical viscoelastic shell. ${ }^{13,16}$ Several of these models are examined further, in the light of measurements, in Refs. 15, 18, and 19. Estimates of the swimbladder contribution derived from some of the cited studies are presented in Table $I$.

The problem common to the various investigations, which is also a cause of the differing results, is that of preserving boundary conditions. The swimbladder is generally aspherical ${ }^{1,15,16}$ and cannot be approximated by a simple geometric shape except possibly at rather low frequencies. In addition, the swimbladder is supported unequally by the surrounding tissue. ${ }^{20}$ This was observed dramatically in a recent series of radiographic observations of the swimbladder of several fish sub-

TABLE I. Estimates of the swimbladder contribution to fish backscattering cross sections derived from earlier studies.

\begin{tabular}{|c|c|c|c|c|}
\hline Method & Objects of acoustic comparison & $\begin{array}{l}\text { Frequencies } \\
\quad(\mathrm{kHz})\end{array}$ & $\begin{array}{l}\text { Swimbladder contribution } \\
\text { (percentage) }\end{array}$ & Ref. \\
\hline Experiment & $\begin{array}{l}\text { Gutted cod of } 60-75 \mathrm{~cm} \text { length } \\
\text { and model swimbladders with } \\
\text { equivalent swimbladder volume }\end{array}$ & $10,14,30$ & $35-70$ & 1 \\
\hline Experiment & $\begin{array}{l}\text { Perch of } 20 \mathrm{~cm} \text { length with } \\
\text { full and deflated swimbladders }\end{array}$ & 30 & 50 & 2 \\
\hline Experiment & $\begin{array}{l}1 \text { crappie }(32 \mathrm{~cm}), 1 \text { large mouth } \\
\text { bass }(40 \mathrm{~cm}), \text { and } 2 \text { yellowfin } \\
\text { tuna }(69 \text { and } 73 \mathrm{~cm}) \text { with full } \\
\text { and deflated swimbladders }\end{array}$ & $\begin{array}{l}20,40 \\
50,280\end{array}$ & $20-80$ & 5 \\
\hline Experiment & $\begin{array}{l}\text { Rubber cylinders of lengths from } \\
14 \text { to } 30 \text { acoustic wavelengths } \\
\text { with and without air-filled } \\
\text { cylindrical cavities }\end{array}$ & 1480 & $30-90$ & 8 \\
\hline Theory & Same rubber cylinders as above & 1480 & 96 & 8 \\
\hline Experiment & $\begin{array}{l}1 \text { cod }(62 \mathrm{~cm}) \text { with and without } \\
\text { its swimbladder }\end{array}$ & 278 & 20 & 10 \\
\hline Experiment & $\begin{array}{l}140 \text { "Funa" of lengths from about } \\
1 \text { to } 20 \text { acoustic wavelengths at } \\
\text { each frequency with and without } \\
\text { their swimbladders }\end{array}$ & 50,200 & 68 & 14 \\
\hline
\end{tabular}


jected to large external pressure changes. ${ }^{21}$

The present study attempts to preclude all considerations of boundary conditions by direct comparison of measured backscattering cross sections of gadoids and mackerel, which respectively possess and lack a swimbladder, but are otherwise similar in size, shape, and, to an extent, anatomy.

\section{DATA BASE AND ANALYSIS}

The data base of this study consists in Nakken and Olsen's measurements of the dorsal aspect target strength functions of three gadoid species and mackerel at 38 and $120 \mathrm{kHz}^{22,23}$ Only those measurements corresponding to fish with lengths from 29 to $42 \mathrm{~cm}$ are used. This length range represents the extent of the mackerel measurements, which is more limited than that of any of the gadoid species. The numbers of available target strength functions are described by species and frequency in Table II.

These data have been prepared for further analysis by extraction of maximum values and by averaging of each dorsal aspect function. The averaging proceeds according to the model described in detail in Ref. 24 and used elsewhere. ${ }^{25-30}$ For present purposes it is sufficient to consider ensonification of fish by a directional echo sounder. The position and orientation of fish in the echo sounder beam are described by probability distribution functions which are, respectively, uniform and essentially normal in tilt angle. Independence of the two distributions, which is tantamount to neglecting avoidance reaction, ${ }^{30,31}$ is also reasonable for the intended computations here.

The tilt angle distribution is defined precisely as a normal distribution which is truncated at angles departing from the mean by three standard deviations. Empirical justification for use of this distribution is presented in Refs. 32 and 33. The mean and standard deviation of the nontruncated distribution are chosen to be 0 and 10 $\mathrm{deg}$, which are characteristic of a rather loose aggregation. ${ }^{28}$ For these parameter values the noted deficiencies of some of the mackerel data in Ref. 23 are entirely negligible.

The echo sounder is represented by beam patterns equivalent to that of an ideal circular piston with halfbeamwidth, or angular distance from acoustic axis to $-3 \mathrm{~dB}$ level, of $2.5 \mathrm{deg}$.
Possible systematic species differences in the gadoid target strength data are ignored. The merged data are distinguished only by target strength type and frequency. These are compared with corresponding target strengths for mackerel. To facilitate this comparison, the target strengths of each set are regressed linearly on fish length according to the prescription

$$
\mathrm{TS}=m \log l+b,
$$

where TS is the target strength predicted for fish of length $l$, expressed in centimeters, and $m$ and $b$ are the estimated regression coefficients. Evidence for the validity of linear regression analysis of similar target strength data is cited in Ref. 26.

In order to determine the contribution of the swimbladder to the backscattering cross section, the target strength of Eq. (1) is expressed as a cross section $\sigma$ according to the definition

$$
\mathrm{TS}=10 \log (\sigma / 4 \pi) \text {. }
$$

The units of TS are decibels and $\sigma$, square meters, such that the idealized perfectly reflecting sphere of $2 \mathrm{~m}$ radius has a target strength of $0 \mathrm{~dB}$.

\section{Swimbladder contribution}

The contribution of the swimbladder to the backscattering cross section is defined here by the relative quantity

$$
1-\sigma_{2} / \sigma_{1}
$$

where $\sigma_{1}$ and $\sigma_{2}$ are the respective backscattering cross sections of gadoids and mackerel of the same length. Since $\sigma_{1}$ and $\sigma_{2}$ are derived from data which are intrinsically stochastic on the scale size of measurement, the swimbladder contribution is specified within limits that obtain with a given probability, say $1-\alpha$. If the cumulative distribution function of the gadoid target strength variable $y_{1}$ is denoted $F_{1}\left(y_{1}\right)$ and the probability density function of the mackerel target strength variable $y_{2}$ is denoted $f_{2}\left(y_{2}\right)$, then

$$
1-10^{-d_{1}} / 10 \leqq 1-\sigma_{2} / \sigma_{1} \leqq 1-10^{-d_{2}} / 10
$$

with probability $1-\alpha$, where $d_{1}$ and $d_{2}$ are determined by numerical solution of the equation

$$
\int_{-\infty}^{\infty} F_{1}(y+d) f_{2}(y) d y=\left\{\begin{array}{l}
\alpha / 2, \text { for } d=d_{1}, \\
1-\alpha / 2, \text { for } d=d_{2} .
\end{array}\right.
$$

\begin{tabular}{|c|c|c|}
\hline \multirow[b]{2}{*}{ Species } & \multicolumn{2}{|c|}{ Numbers of target strength functions } \\
\hline & Frequency $=38 \mathrm{kHz}$ & Frequency $=120 \mathrm{kHz}$ \\
\hline $\begin{array}{l}\text { Cod } \\
\text { (Gadus morhua) }\end{array}$ & 22 & 12 \\
\hline $\begin{array}{l}\text { Saithe } \\
\text { (Pollachius virens) }\end{array}$ & 17 & 12 \\
\hline $\begin{array}{l}\text { Pollack } \\
\text { (Pollachius pollachius) }\end{array}$ & 11 & 11 \\
\hline $\begin{array}{l}\text { Mackerel } \\
\text { (Scomber scombrus) }\end{array}$ & $35^{\circ}$ & 24 \\
\hline
\end{tabular}

TABLE II. Numbers of available and analyzed target strength functions of gadoids and mackerel with lengths from 29 to $42 \mathrm{~cm}$ as distinguished by species and frequency. 
This last equation simply expresses the probability that the difference of the two independent random variables $y_{1}$ and $y_{2}$ does not exceed the values $d_{1}$ or $d_{2} \cdot{ }^{34}$ According to the plausible hypotheses on which the linear regression analyses are based, each distribution is normal. For fish of length $l$ in the interval $[29,42] \mathrm{cm}$ the defining parameters of the distribution of target strength variable $y$ are the mean

$$
\bar{y}=m \log l+b
$$

and standard deviation

$$
s_{y}=s_{y \cdot x}\left(n^{-1}+(l-\bar{x})^{2} / \sum_{i}\left(x_{i}-\bar{x}\right)^{2}\right)^{1 / 2},
$$

where $s_{y \cdot x}$ is the standard error of the regression, $x_{i}$ is the logarithm of length for a single datum, and $\bar{x}$ is the mean of the logarithmically transformed lengths of all $n$ data underlying the regression.

\section{RESULTS}

Target strengths cor responding to the data enumerated in Table II are presented on scatter diagrams in Figs. 1-4. The maximum dorsal aspect target strengths of Figs. 1 and 3 were derived by simple extraction from the data presented in Ref. 23. The target strengths of Figs. 2 and 4 were derived from the data of the same reference by the averaging method outlined above and described fully in Ref. 24.

Results of regressing both the merged gadoid target strengths and mackerel target strengths on fish length for the various data sets are described in Table III. There the estimated standard errors of estimated regression coefficients are denoted $s_{m}$ and $s_{b}$. The standard error of the regression is denoted SE. The correlation coefficient $\rho$ of data is attached for reference. The described linear regressions are shown on the figures.

The principal results of the study are shown in Fig. 5. This is composed of four sets of figures, corresponding to Figs. 1-4, which express the relative swimbladder contribution as a percentage. The contribution is described within limits that obtain with probability 0.95 .

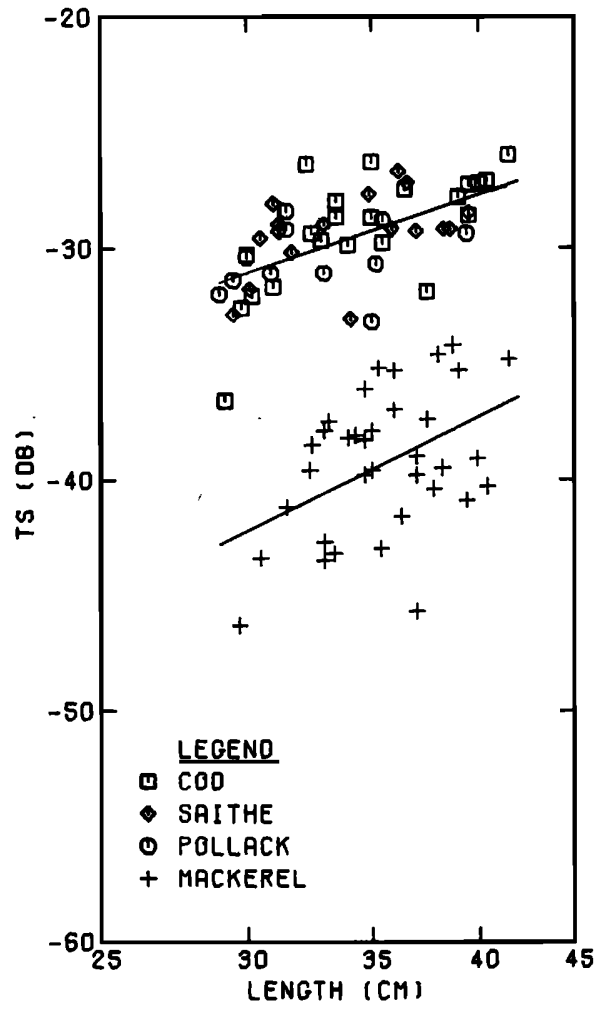

FIG. 1. Scatter diagrams with regressions of maximum dorsal aspect target strengths on length for merged gadoids and for mackerel at $38 \mathrm{kHz}$.

\section{DISCUSSION}

The target strength data of each of Figs. 1-4 are divisible into two groups with only a small "gray zone" of possible ambiguity or overlap. The gadoid data are apparently homogeneous, which justifies their merging. General systematic species differences among gadoid target strength data ${ }^{26-28}$ are probably absent in the present case because of the particular, narrow, length range of the data. The mackerel data are similarly homogeneous, although more dispersed. Both the gadoid and mackerel target strength data are assumed to be amenable to linear regression analysis, which is supported by the analysis of Table III and other computations. ${ }^{26}$

TABL̇E III. Regression analyses of maximum and averaged target strengths on fish length for gadoid and mackerel data at 38 and $120 \mathrm{kHz} . m$ and $b$ are the estimated regression coefficients, cf. Eq. (1); $s_{m}$ and $s_{b}$, the corresponding standard errors; SE, the standard error of the regression;

\begin{tabular}{|c|c|c|c|c|c|c|c|c|}
\hline TS-type & Fish & $\begin{array}{c}\text { Frequency } \\
(\mathbf{k H z})\end{array}$ & $m$ & $s_{m}$ & $b$ & $s_{b}$ & $\mathrm{SE}$ & $\rho$ \\
\hline Maximum & Gadoids & 38 & 27.1 & 5.6 & -71.7 & 8.6 & 1.8 & 0.572 \\
\hline Maximum & Mackerel & 38 & 39.6 & 13.9 & -100.7 & 21.5 & 2.8 & 0.445 \\
\hline Average & Gadoids & 38 & 23.8 & 5.5 & -71.3 & 8.4 & 1.7 & 0.532 \\
\hline Average & Mackerel & 38 & 39.8 & 14.9 & -106.3 & 23.0 & 3.0 & 0.423 \\
\hline Maximum & Gadoids & 120 & 27.2 & 7.1 & -70.4 & 10.9 & 1.8 & 0.553 \\
\hline Maximum & Mackerel & 120 & 54.7 & 17.8 & -125.0 & 27.6 & 3.3 & 0.547 \\
\hline Average & Gadoids & 120 & 22.9 & 6.2 & -71.2 & 9.5 & 1.6 & 0.541 \\
\hline Average & Mackerel & 120 & 53.7 & 19.5 & -130.2 & 30.2 & 3.6 & 0.506 \\
\hline
\end{tabular}
and $\rho$, the correlation coefficient. 
The backscattering cross sections and associated statistics derived from the regression analyses were used, as in Eqs. (3) and (4), to determine the swimbladder contribution to the backscattering cross section. It is reasoned that this contribution can be estimated as the difference in cross sections of anatomically comparable fish, of the same length or mass, which respectively possess and lack a swimbladder. The cross section of a bladderless fish is thus taken to be a measure of the cumulative scattering power of fish flesh, bone, and other organs. While the backscattering cross section of an individual fish is a sensitive function of its precise composition, ${ }^{7,10,17}$ it is reasonable to assume that individual variations are smoothed out through the kind of regression analysis performed here. Because gadoids and mackerel are approximately similar in their gross anatomy and fusiform shapes, the difference in cross sections may be accepted as a measure of the scattering strength of the swimbladder. The similarity in condition factors for the mackerel and gadoids of measurement ${ }^{35}$ supports the comparison of the target strengths, as presented in Figs. 1-4, both for fish of the same mass and for fish of the same length.

From the several parts of Fig. 5, the swimbladder contribution to the backscattering cross sections of gadoids is observed to be about $90 \%$ to $95 \%$. This is higher than that of many earlier studies, cf. Table I, for example, but is entirely consistent with Yudanov's $a$ posteriori assertion that the swimbladder contributes at least $90 \%$, and often much more, to the backscattering cross section. ${ }^{36}$

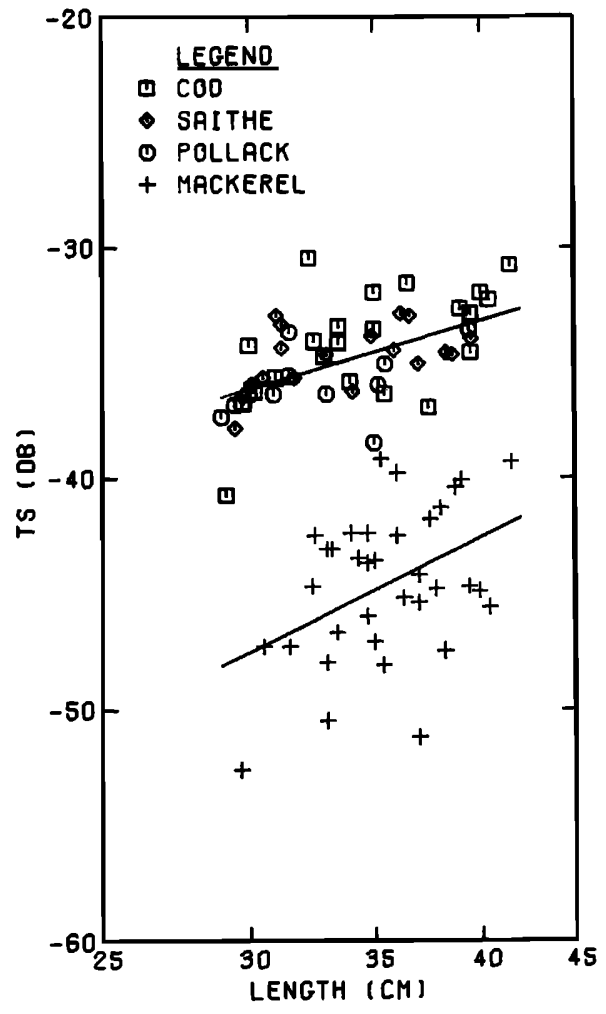

FIG. 2. Scatter diagrams with regressions of averaged dorsal aspect target strengths on length for merged gadoids and for mackerel at $38 \mathrm{kHz}$.

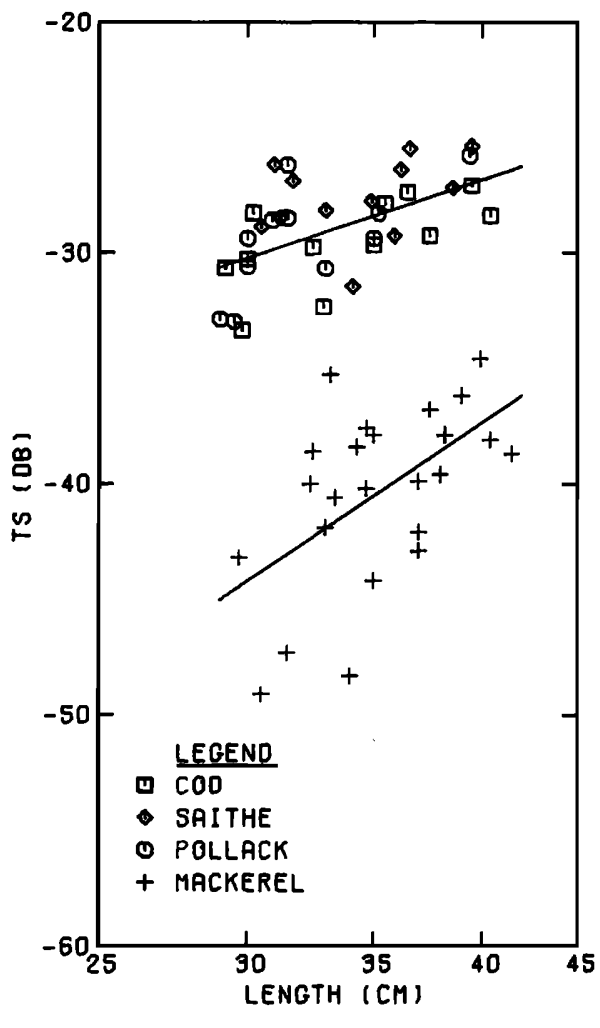

FIG. 3. Scatter diagrams with regressions of maximum dorsal aspect target strengths on length for merged gadoids and for mackerel at $120 \mathrm{kHz}$.

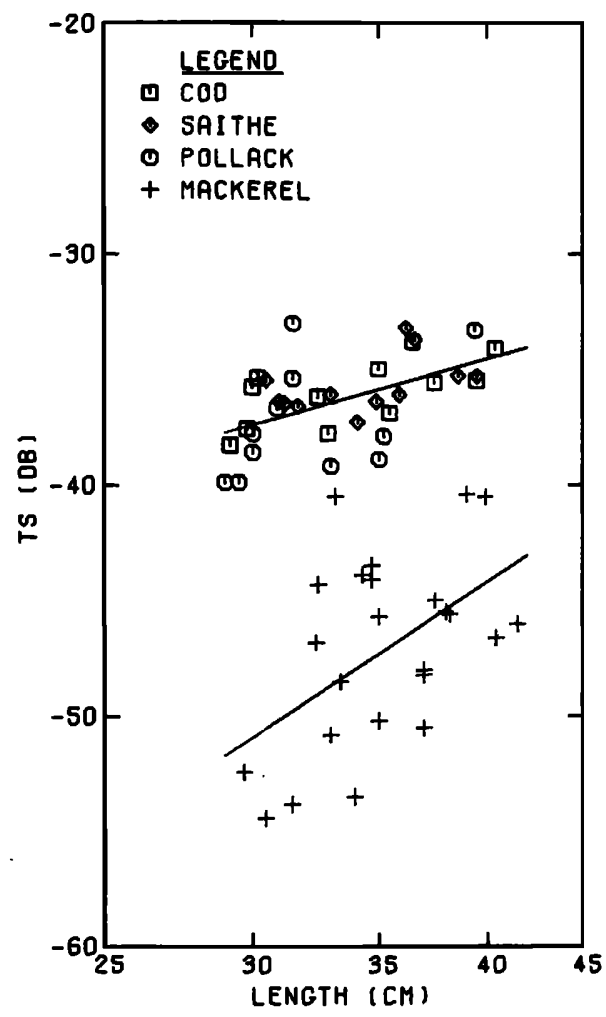

FIG. 4. Scatter diagrams with regressions of averaged dorsal aspect target strengths on length for merged gadoids and for mackerel at $120 \mathrm{kHz}$. 


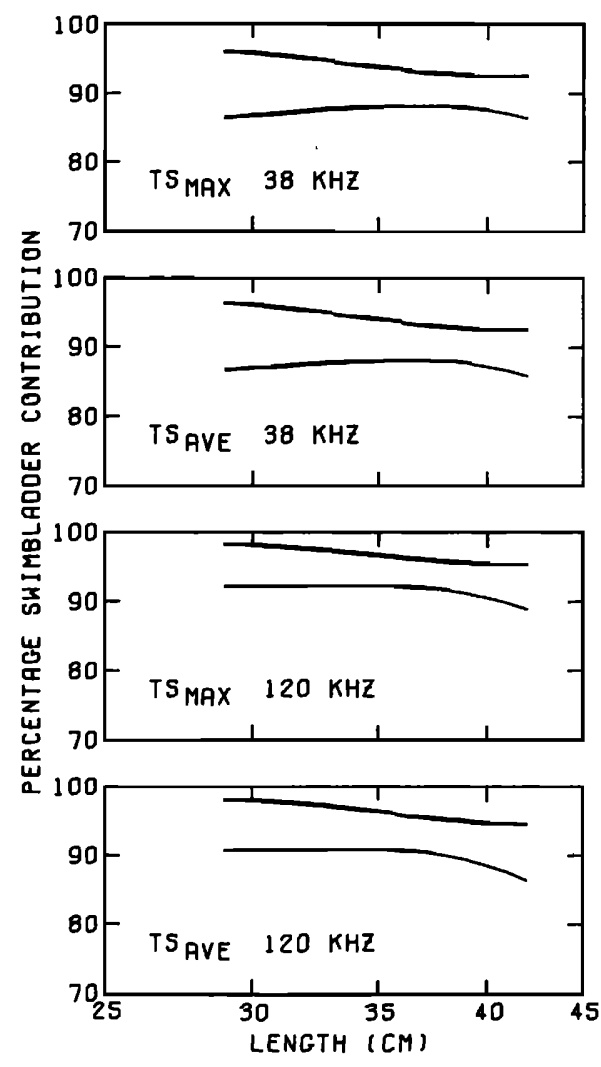

FIG. 5. Percentage swimbladder contribution to maximum and averaged dorsal aspect backscattering cross sections of fish at 38 and $120 \mathrm{kHz}$, with $95 \%$ confidence as defined by the data of Figs. 1-4.

Differences in results between this study and the cited earlier studies are attributed both to differences in the particular species and acoustic frequencies of investigation and to the methods of analysis. The advantage of the present method is that it avoids altering the basic boundary conditions at the swimbladder wall-the interface between the acoustically lossy and elastic fish flesh and strongly reflecting gas sac of the swimbladder.

In revising upwards previous estimates of the scattering contribution of the swimbladder, at least for gadoids at typical ultrasonic survey frequencies, the present study may provide a new impetus to acoustic modelling of swimbladder-bearing fish. This is anticipated to be equally applicable to physoclists and physostomes.

${ }^{1}$ D. H. Cushing and I. D. Richardson, "Echo sounding experiments on fish," Fish. Invest. Lond., Ser. 2 18(4), 1-34 (1955).

${ }^{2}$ F. R. Harden Jones and G. Pearce, "Acoustic reflexion experiments with perch (Perca fluviatilis Linn) to determine the proportion of the echo returned by the swimbladder," J. Exp. Biol. 35, 437-450 (1958).

${ }^{3} \mathrm{~L}$. Midttun and I. Hoff, "Determination of the reflection of sound by fish," Fiskdir. Skr. Ser. Havunders. 13(3), 1-18 (1962).

${ }^{4}$ D. H. Cushing, F. R. Harden Jones, R. B. Mitson, G. H. Ellis, and G. Pearce, "Measurements of the target strength of fish," J. Br. Inst. Radio Eng. 25, 299-303 (1963).
${ }^{5} \mathrm{H}$. W. Volberg, “Target strength measurements of fish," Straza Industries, El Cajon, California, Report R-101 (1963).

G. B. Andreeva, "Scattering of sound by air bladders of fish in deep sound-scattering ocean layers," Sov. Phys.-Acoust. 10, 17-20 (1964).

${ }^{7}$ R. W. G. Haslett, "Acoustic backscattering cross sections of fish at three frequencies and their representation on a universal graph," Br. J. Appl. Phys. 16, 1143-1150 (1965).

${ }^{8}$ R. W. G. Haslett, "Acoustic backscattering from an air-filled cylindrical hole embedded in a sound-translucent cylinder," Br. J. Appl. Phys. 17, 549-561 (1966).

${ }^{9}$ R. W. G. Haslett, "Automatic plotting of polar diagrams of target strength of fish in roll, pitch and yaw," Rapp. P.-V. Reun. Cons. Int. Explor. Mer. 170, 74-81 (1977).

${ }^{10}$ R. W. G. Haslett, "The fine structure of sonar echoes from underwater targets, such as fish," in Ultrasonics International 79 Conference Proceedings (IPC, Guildford, England, 1979), pp. 307-320.

${ }^{11}$ R. L. Capen, "Swimbladder morphology of some mesopelagic fishes in relation to sound scattering," Navy Electronics Laboratory, San Diego, California, Report 1447 (1967).

${ }^{12} \mathrm{D}$. E. Weston, "Sound propagation in the presence of bladder fish," in Underwater Acoustics, edited by V. M. Albers (Plenum, New York, 1967), Vol. 2, Chap. 5, pp. 55-88.

${ }^{13}$ B. S. McCartney and A. R. Stubbs, "Measurements of the acoustic target strengths of fish in dorsal aspect, including swimbladder resonance," J. Sound Vib. 15, 397-420 (1971).

${ }^{14} \mathrm{~K}$. Shibata, "Experimental measurement of target strength of fish," in Modern Fishing Gear of the World: 3, edited by H. Kristjonsson [Fishing News (Books) Ltd., London, 1971], pp. 104-108.

${ }^{15} \mathrm{~A}$. D. Hawkins, "Fish sizing by means of swimbladder resonance," Rapp. P.-V. Reun. Cons. Int. Explor. Mer. 170, 122-129 (1977).

${ }^{16} \mathrm{R}$. H. Love, "Resonant acoustic scattering by swimbladderbearing fish," J. Acoust. Soc. Am. 64, 571-580 (1978).

${ }^{17} \mathrm{~K}$. I. Yudanov and I. L. Kalikhman, "Acoustic characteristics of marine animals," in Proceedings of the Meeting on Hydroacoustical Methods for the Estimation of Marine Fish Ropulations, edited by J. B. Suomala, Jr. (Draper Laboratory, Cambridge, MA, in press), Vol. 2.

${ }^{18} \mathrm{O}$. Sand and A. D. Hawkins, "Acoustic properties of the cod swimbladder," J. Exp. Biol. 58, 797-820 (1973).

${ }^{19} \mathrm{G}$. Sundnes and $O$. Sand, "Studies of a physostome swimbladder by resonance frequency analyses, " J. Cons. Int. Explor. Mer 36, 176-182 (1975).

${ }^{20} \mathrm{P}$. Tytler and J. H. S. Blaxter, "The effect of swimbladder deflation on pressure sensitivity in the saithe Pollachius

virens," J. Mar. Biol. Assoc. U. K. 57, 1057-1064 (1977).

${ }^{21} \mathrm{~K}$. G. Foote and E. Ona, "Radiographic study of gross changes in swimbladder shape under systematic pressure changes," (in preparation).

${ }^{22} \mathrm{O}$. Nakken and K. Olsen, "Target strength measurements of fish," Rapp. P.-V. Reun. Cons. Int. Explor. Mer. 170, 52-69 (1977).

${ }^{23} \mathrm{~K}$. G. Foote and O. Nakken, "Dorsal aspect target strength functions of six fishes at two ultrasonic frequencies," Fisken og Havet, Ser. B., 1978, No. 3, 95 pp.

${ }^{24} \mathrm{~K}$. G. Foote, "Averaging of fish target strength functions," J. Acoust. Soc. Am. 67, 504-515 (1980).

${ }^{25} \mathrm{~K}$. G. Foote, "Effect of fish behaviour on echo energy: the need for measurements of orientation distributions," J. Cons. Int. Explor. Mer. 39 (in press).

${ }^{26} \mathrm{~K}$. G. Foote, "On representing the length dependence of acoustic target strengths of fish," J. Fish. Res. Board Can. 36, 1490-1496 (1979).

${ }^{27}$ K. G. Foote, "Fish target strength-to-length regressions for application in fisheries research," in Uttrasonics International 79 Conference Proceedings (IPC, London, 1979), pp. 327-332. 
${ }^{28} \mathrm{~K}$. G. Foote, "Systematic species and frequency dependent differences among gadoid target strength functions," in Proceedings of the Meeting on Hydroacou stical Methods for the Estimation of Marine Fish Populations, edited by J. B. Suomala, Jr. (Draper Laboratory, Cambridge, MA, in press), Vol. 2.

${ }^{29} \mathrm{~K}$. G. Foote, "Evidence for the influence of fish behaviour on echo energy," in Proceedings of the Meeting on Hydroacoustical Methods for the Estimation of Marine Fish Populations, edited by J. B. Suomala, Jr. (Draper Laboratory, Cambridge, MA, in press), Vol. 2.

${ }^{30} \mathrm{~K}$. G. Foote, "Biasing of fish abundance estimates derived from use of the sector scanning sonar in the vertical plane," in Proceedings of the Conference 'Progress in Sector Scanning Sonar' (Institute of Acoustics, Edinburgh, 1979), pp. 44-52.
${ }^{31} \mathrm{~K}$. Olsen, "Observed avoidance behaviour in herring in relation to passage of an echo survey vessel," ICES C. M. 1979/B:18, $10 \mathrm{pp}$.

${ }^{32} \mathrm{~K}$. Olsen, "Orientation measurements of cod in Lofoten obtained from underwater photography and their relation to target strength," ICES C. M. 1971/B:17, 8 pp.

${ }^{33} \mathrm{~A}$. K. Beltestad, "Feeding, vertical migration, and schooling of 0-group herring (Clupea harengus L.) in relation to light intensity," Dissertation, University of Bergen (1974) (in Norwegian).

${ }^{34}$ S. S. Wilks, Mathematical Statistics (Wiley, New York, 1962), $644 \mathrm{pp}$.

${ }^{35} \mathrm{E}$. Bakken (unpublished data).

${ }^{36} \mathrm{~K}$. I. Yudanov, statement at the Meeting on Hydroacoustical Methods for the Estimation of Marine Fish Populations, Draper Laboratory, Cambridge MA, 1979 (unpublished). 